OPEN ACCESS

Edited by:
Lino Nobili,

Reviewed by:

Axel Steiger,

Max-Planck-Institut für Psychiatrie,

Germany

F. Javier Puertas,

University Hospital of Liege, Belgium

*Correspondence:

Frédéric Roche

frederic.roche@univ-st-etienne.fr

Specialty section:

This article was submitted to

Sleep and Chronobiology,

a section of the journal

Frontiers in Neurology

Received: 11 May 2018 Accepted: 10 October 2018

Published: 31 October 2018

Citation:

Sforza E, Hupin D and Roche F (2018)

Mononucleosis: A Possible Cause of

Idiopathic Hypersomnia.

Front. Neurol. 9:922.

doi: 10.3389/fneur.2018.00922

\section{Mononucleosis: A Possible Cause of Idiopathic Hypersomnia}

\author{
Emilia Sforza, David Hupin and Frédéric Roche*
}

Service de Physiologie Clinique et de l'Exercice (Pole Hospitalier NOL), CHU Nord, Faculté de Médecine Jacques Lisfranc, Université Jean Monnet, SNA EPIS EA 4607, Université de Lyon, Saint-Étienne, France

Idiopathic hypersomnia $(\mathrm{IH})$ is a rare central hypersomnia of unknown physiopathology. In this study, we determine if the presence of infectious mononucleosis evaluated by serological markers of Epstein Barr virus infection plays a role in this hypersomnia. Ten patients with a suspicion of $\mathrm{IH}$ underwent to clinical assessment, $24 \mathrm{~h}$ polysomnography, and serologic testing for mononucleosis including Viral Capside Antigen (VCA) IgG, the VCA IgM, and the EBV nuclear antigen (EBNA). None of the patients reported neurological inflammatory disease and viral infection prior the onset of the disease. Compared to the laboratory serological reference values, all patients had high levels of VCA IgG and EBNA with lower level of VCA IgM, overall indicating past infection. This study shows that prior infectious mononucleosis may predispose some subjects to idiopathic hypersomnia suggesting the role of inflammatory and immunological processes in this sleep disorder.

Keywords: Idiopathic hypersomnia, mononucleosis, inflammation, immunological processes, exessive daytime sleepiness

\section{INTRODUCTION}

Idiopathic hypersomnia (IH) affects more frequently young adults and comprise a combination of symptoms characterized by daytime sleepiness and a decreases amount of alertness during daytime despite long sleep time lasting more than $10 \mathrm{~h}(1,2)$. Associated symptoms are long and un-refreshing naps, difficulty waking up, sleep drunkenness in the morning, sometimes depressive and anxiety symptoms, and a tendency to sleep phase delay (3). The diagnosis of IH relies on the exclusion of other cases of hypersomnia secondary to other sleep disorders, i.e., narcolepsy without cataplexy, sleep related breathing disorder, periodic legs syndrome, sleep deprivation, irregular sleep schedule and/or to head trauma, medication use, substance abuse or neurological diseases such as myotonic dystrophy and multiple sclerosis (4).

Although the clinical spectrum of $\mathrm{IH}$ is to date well defined, the pathogenesis remains largely unknown. A previous study (5) examining the published cases of symptomatic narcolepsy and HI conclude that despite the lack of hypocretin ligand deficiency in the symptomatic cases the hypothesis of hypothalamic lesions involving the orexin system may be hypothesized. Moreover, since histamine is one of most important neurotransmitter promoting wakefulness, in animal $(6,7)$ and humans (8), a study (9) in patients with narcolepsy, idiopathic hypersomnia or obstructive sleep apnea shown reduced cerebrospinal fluid histamine levels only in narcolepsy and $\mathrm{HI}$ cases suggesting the hypothesis of a lowering of histamine levels in central hypersomnia. In a paper published by Guilleminault and Mondini (10), the authors reported the presence of daytime sleepiness in 10 patients suspected to have Epstein-Barr viral infection in some cases with immunological 
neurological diseases and persisting 3 to 12 years after the diagnosis of infectious mononucleosis. To test the hypothesis if mononucleosis or asymptomatic Epstein-Barr virus seroconversion may predispose to hypersomnia we made systematic serological testing in a consecutive patients with diagnosed $\mathrm{IH}$.

\section{METHODS}

\section{Population}

Over a 5-year period, 20 patients aged $26.1 \pm 9$ years (range 18-56 years) coming to our sleep clinics for hypersomnia and daytime sleepiness were examined by a face-to-face clinical interview, sleep diary, 2-weeks actimetry and $24 \mathrm{~h}$ polysomnography. Among this sample, 14 patients meet the criteria for idiopathic hypersomnia, that is complaints of excessive daytime sleepiness for $>1$ year; - a night-time length $>10$ h for 3 weeks before polysomnography assessed by sleep diary; - the absence of narcolepsy-cataplexy, sleep irregularities and sleep deprivation symptoms; - lack of neurological or psychiatric diseases and respiratory and/or motor sleep disorders. Ten patients free of medication meet all the inclusion criteria and accepted blood samples including analysis for mononucleosis infection.

The local Ethics Committee approved the study. All patients gave their written inform consent prior to participation in the study.

\section{CLINICAL, MICROBIOLOGICAL, AND INSTRUMENTAL ASSESSMENT}

\section{Clinical Assessment}

Clinical evaluation for patients was assessed by a standard clinical interview, which included history of the actual symptoms, the age of onset of the symptoms, their familiarity, the usual sleepwake rhythm during working period and week-end period, the difficulties to waking up and the methods used to wake up and the number, type (refreshing/unrefreshing), and duration of naps. HAD scale as well as Beck questionnaire allowed us to exclude underlying depressive pathology or disease anxiety. Symptomatology suggestive of dysautonomia was questioned. The presence of orthostatic hypotension with syncope was found in 4 patients and the presence of chronic non-migraine headache in 2 others. There was no complaint about thermogenesis in this population.

The body mass index (BMI), calculated as weight/height squared $\left(\mathrm{kg} / \mathrm{m}^{2}\right)$, was measured and subjective sleepiness was evaluated using the Epworth Sleepiness Scale (ESS) questionnaire with an ESS $>10$ defining subjective sleepiness.

\section{Serological and Blood Sample Analysis}

Blood sample analysis include screening for diabetes, hypovitaminosis, anemia, iron deficiency, and serology to assess the presence of Epstein-Barr virus (EBV) infection. The serological analyses were made in the same laboratory, using the immunofluorescence assays (11) and including the three common serological tests to diagnose EBV: 1. Viral Capside Antigen (VCA) IgG, VCA IgM, and EBV nuclear antigen
(EBNA). The laboratory serological reference values were respectively: VCA IgG: $<200 \mathrm{U} / \mathrm{ml}$, VCA $\operatorname{IgM}<500 \mathrm{U} / \mathrm{ml}$, Virus Epstein Barr EBNA $<800 \mathrm{U} / \mathrm{ml}$ ). These tests make it possible to define the status of the infection. The presence of VCA IgG and VCA IgM without EBNA indicate acute infection whereas the presence of VCA IgG and EBNA in the absence of VCA IgM is typical of past infection (12). HLA-DRB1*1501-DQB1*0602 haplotype was absent in all patients.

\section{At-Home 24-h Polysomnography Recording}

Actimetric recording prior to polysomnography eliminated sleep phase shift phenomena, sleep restriction. The estimated average sleep time was $605 \pm 40$ min by this Actigraphic method.

In all subjects, a $24 \mathrm{~h}$ ambulatory ad libitum polysomnography was performed including conventional measures: four conventional electroencephalographic tracings, right and left electrooculogram, chin and bilateral anterior tibialis electromyograms, electrocardiogram (ECG), nasal pressure, respiratory effort, body position, and oxygen saturation, the latter is measured by pulse oximetry. All signals were recorded at $256 \mathrm{~Hz}$. During the recording, the subjects were allowed to perform usual activities during daytime period and to sleep whenever they wanted according to their usual bedtime and waking up schedule reported in the sleep diary. Sleep stages were visually scored in 30-s epochs according to standard AASM criteria (13).

\section{RESULTS}

Clinical, polysomnographic and serological data are reported in Table 1. Ten patients aged $21.4 \pm 2.6$ years, nine females and 1 men, with a mean BMI of $21.4 \pm 2.9 \mathrm{~kg} / \mathrm{m}^{2}$ were examined. The mean age of symptoms onset was $18.9 \pm 5.6$ years. and their mean Epworth sleepiness score was $11.3 \pm$ 5.4. All patients had cerebral magnetic resonance imaging that

\begin{tabular}{lc}
\multicolumn{2}{l}{ TABLE 1 | Clinical, biological, and sleep data for all subjects (mean \pm SD). } \\
\hline Age (years) & $22.2 \pm 1.9$ \\
Age of onset (years) & $18.1 \pm 1.5$ \\
Body mass index (kg/m²) & $20.8 \pm 1.7$ \\
Epworth sleepiness scale & $11.2 \pm 0.93$ \\
Total sleep time (min) & $570 \pm 47.5$ \\
Awakenings ( $n$ ) & $14.8 \pm 1.2$ \\
Sleep efficiency (\%) & $93.3 \pm 7.8$ \\
Sleep latency (min) & $16.7 \pm 28.5$ \\
REM latency (min) & $123.5 \pm 61.8$ \\
Stage 1\% & $6.0 \pm 0.5$ \\
Stage 2\% & $52.2 \pm 4.3$ \\
Slow wave sleep \% & $21.0 \pm 1.8$ \\
Rapid-eye-movement sleep\% & $19.8 \pm 5.9$ \\
IgG (U/ml) & $1010.74 \pm 84.2$ \\
IgM (U/mL) & $74.85 \pm 0.6 .2$ \\
EBNA /ml & $1804.3 \pm 150.4$
\end{tabular}


exclude the presence of cerebral lesion. None of the patients had metabolic alterations, including anemia, inflammatory indices and low levels of iron and ferritin. None of the patients reported infection prior the onset of sleepiness and hypersomnia and familiarity for hypersomnia.

The patients slept well with a total sleep time of about $10 \mathrm{~h}$ and a sleep efficiency of $94 \%$ indicating good sleep quality. None of the patients had respiratory events and periodic leg movements. In the bottom part of the Table $\mathbf{1}$ are reported the mean values $\pm \mathrm{SD}$ of the serological results. All patients had high levels of VCA IgG and EBNA with low level of VCA IgM, indicating past infection.

\section{DISCUSSION}

To the best of our knowledge, the present study is the first to evaluate the role of Epstein Barr infection in patients with primary $\mathrm{IH}$ and without neurological disorders. Although none of the patients reported at the beginning of the disease some infection, we found the presence of the classical serological markers of a prior mononucleosis infection. We know that mononucleosis and Epstein-Barr infection are often asymptomatic and the clinical symptoms and their duration are variable. As reported by Lambore and coworkers in student community (14), patients with previous mononucleosis differ from those having other infections for greater and significant tiredness, sleepiness, and depression persisting after 1 year. Overall, these symptoms overlap with "Sickness Syndrome" (15) that is an adaptative host response to infectious in that in addition to fever and hypoferremia fatigue and hypersomnia are present, the last symptoms overlapping those described by $\mathrm{HI}$ patients.

\section{REFERENCES}

1. Anderson KN, Pilsworth S, Sharples S, Sharples LD, Smith IE, Sheerson JM. Idiopathic hypersomnia: a study of 77 cases. Sleep (2007) 30:1274-81. doi: 10.1093/sleep/30.10.1274

2. Billiard M, Dauvilliers Y. Idiopathic hypersomnia. Sleep Med Rev. (2001) 5:349-58. doi: 10.1053/smrv.2001.0168

3. Vernet C, Leu-Semenscu S, Buzare MA, Arnulf I. Subjective symptoms in idiopathic hypersomnia: beyond excessive sleepiness. J Sleep Res. (2010) 19:525-34. doi: 10.1111/j.1365-2869.2010.00824.x

4. Ali M, Auger RR, Slocumb NL, Morgenthaler TI. Idiopathic hypersomnia: clinical features and response to treatment. J Clin Sleep Med. (2009) 5:562-8.

5. Nishino S, Kanbayashi T. Symptomatic narcolepsy, cataplexy and hypersomnia, and their implications in the hypothalamic hypocretin/orexin system. Sleep Med Rev. (2005) 9:269-310. doi: 10.1016/j.smrv.2005.03.004

6. Huang ZL, Mochizuki T, Qu WM, Hong ZY, Watanabe T, Urade Y, et al. Altered sleep-wake characteristics and lack of arousal response to $\mathrm{H} 3$ receptor antagonist in histamine H1 receptor knockout mice. Prog Natl Acad Sci USA. (2006) 103:4687-92. doi: 10.1073/pnas.0600451103

7. Lin JS. Brain structures and mechanisms involved in the cortical activation and wakefulness, with emphasis on the posterior hypothalamus and histaminergic neurons. Sleep Med Rev. (2000) 4:471-503. doi: 10.1053/smrv.2000.0116

8. Roehrs TA, Tietz EI, Zorick FJ, Roth T. Daytime sleepiness and antihistamines. Sleep (1984) 7:137-41. doi: 10.1093/sleep/7.2.137
Our study has several limitations. The first one is represented by the fact that not all patients met the ICSD-3 criteria for IH definition. In particular, 4 of them did not have a TST $>660 \mathrm{~min}$ on $24 \mathrm{~h}$ polysomnography. However, the clinical picture was obvious (as well as the actimetry) and the subsequent follow-up of these 4 patients confirmed the presence of chronic hypersomnia. The lack of systematic realization of multiple sleep latency test (MSLT) is also a diagnostic limit (to eliminate type 2 narcolepsy) even if we know the limits of this test in sensitivity and specificity (16) in such a hypersomnia.

The second one is the absence of a control group in our study. However, the seroconversion rate for the Epstein-Bar virus is fairly well described in the literature and never reaches 100\% (as we observed in our IH population) in all the cohorts of students assessed at college entry in the United States (17).

Our findings supports the hypothesis (18) of a possible role of autoinflammatory processes and immune dysregulation mechanism in young adults with $\mathrm{IH}$.

\section{AUTHOR CONTRIBUTIONS}

ES: patients examination, scoring the PSG, design of the study, writing the manuscript; $\mathrm{DH}$ : writing and editing the manuscript; FR: design of the study, writing the manuscript (more particularly: table, methods).

\section{ACKNOWLEDGMENTS}

The authors would like to acknowledge all patients participating to the study and the DRCI from Saint Etienne University Hospital.

9. Kanbayashi T, Kodama T, Kondo H, Satoh S, Inoue Y, Chiba S, et al. CSF histamine contents in narcolepsy, idiopathic hypersomnia and obstructive sleep apnea. Sleep (2009) 32:181-7. doi: 10.1093/sleep/32.2.181

10. Guilleminault C, and Mondini S. Mononucleosis and chronic daytime sleepiness. A long-term follow-up study. Arch Intern Med. (1986) 146:1333-5. doi: 10.1001/archinte.1986.00360190107014

11. Corrales I, Giménez E, Navarro D. Evaluation of the architect Epstein-BarrVirus (EBV) viral capsid antigen (VCA) IgG, IgM, and EBV nuclear antigen IIgG chemoluminiscent immunoassays for detection of EBV antibodies and categorization of EBV infection status using immunofluorescence assays as the reference method. Clin Vacc Immunol. (2014) 21:684-8. doi: 10.1128/CVI.00104-14

12. De Pascale M, Clerici P. Serological diagnosis of Epstein-Barr virus infection: problems and solutions. World J Virol. (2012) 1:31-43 doi: 10.5501/wjv.v1.i1.31

13. Iber C, Ancoli-Israel S, Chesson AL, Quan SF. The AASM Manual for the Scoring of Sleep and Associated Events: Rules, Terminology, and Technical Specifications, 1st Edn. Westchester, IL: American Academy of Sleep Medicine (2007).

14. Lambore S, McSherry J, Krauss AS. Acute and chronic symptoms of mononucleosis. Am Pract. (1991) 33:33-7.

15. Shakar K, Shakar G. Why do feel sick when infected - can altruism plays a role? PLoS Biol. (2015) 13:e1002276. doi: 10.1371/journal.pbio.1002276

16. Billard M, Sonka K. Idiopathic hypersomnia. Sleep Med Rev. (2016) 29:23-33. doi: 10.1016/j.smrv.2015.08.007 
17. Crawford DH, Macsween KF, Higgins CD, Thomas R, McAulay $\mathrm{K}$, Williams $\mathrm{H}$, et al. A cohort study among university students: identification of risk factors for epstein-barr virus seroconversion and infectious mononucleosis. Clin Infect Dis. (2006) 43:276-82. doi: 10.1086/ 505400

18. Barateau L, Lopez R, Arnulf I, Lecendreux M, Franco P, Drouot X, et al. Comorbidity between central disorders of hypersomnolence and immune-based disorders. Neurology (2017) 88:93-100. doi: 10.1212/WNL.00000000000 03432
Conflict of Interest Statement: The authors declare that the research was conducted in the absence of any commercial or financial relationships that could be construed as a potential conflict of interest.

Copyright $\odot 2018$ Sforza, Hupin and Roche. This is an open-access article distributed under the terms of the Creative Commons Attribution License (CC BY). The use, distribution or reproduction in other forums is permitted, provided the original author(s) and the copyright owner(s) are credited and that the original publication in this journal is cited, in accordance with accepted academic practice. No use, distribution or reproduction is permitted which does not comply with these terms. 